\title{
Material Interactions in Laser Polishing Powder Bed Additive Manufactured Ti6AI4V Components
}

\author{
Yingtao Tian ${ }^{1}$, Wojciech S. Gora ${ }^{2}$, Aldara Pan Cabo ${ }^{2}$, Lakshmi L. Parimi ${ }^{3}$, \\ Duncan P. Hand ${ }^{2}$, Samuel Tammas-Williams ${ }^{1}$, Philip B. Prangnell ${ }^{1}$ \\ ${ }^{1}$ School of Materials, University of Manchester, Manchester, M13 9PL, UK \\ ${ }^{2}$ School of Engineering \& Physical Sciences, Heriot-Watt University, Edinburgh, EH14 4AS, \\ UK \\ ${ }^{3}$ GKN Aerospace, Filton, Bristol, BS34 9AU, UK
}

\begin{abstract}
Laser polishing (LP) is an emerging technique with the potential to be used for post-build, or in-situ, precision smoothing of rough fatigue-initiation prone surfaces of additive manufactured (AM) components. LP uses a laser to re-melt a thin surface layer and smooths the surface by exploiting surface tension effects in the melt pool. However, rapid resolidification of the melted surface layer and the associated substrate thermal exposure can significantly modify the subsurface material. This study has used an electron beam melted (EBM) Ti6A14V component, representing the worst case scenario in terms of roughness for a powder bed process, as an example to investigate these issues and evaluate the capability of the LP technique for improving the surface quality of AM parts. Experiments have shown that the surface roughness can be reduced to below $\mathrm{Sa}=0.51 \mu \mathrm{m}$, which is comparable to a CNC machined surface, and high stress concentrating defects inherited from the AM process were removed by LP. However, the re-melted layer underwent a change in texture, grain structure, and a martensitic transformation, which was subsequently tempered in-situ by repeated beam rastering and resulted in a small increase in sub-surface hardness. In addition, a high level of near-surface tensile residual stresses was generated by the process, although they could be relaxed to near zero by a standard stress relief heat treatment.
\end{abstract}

Key Words: Additive Manufacturing; Laser Polishing; Titanium; Microstructure; Residual Stresses. 


\section{Introduction}

Recent developments in metal powder-based additive manufacturing (AM) technologies have stimulated great interest in many industrial sectors. Selective laser melting (SLM) and electron beam melting (EBM) powder bed processes and laser metal deposition (LMD) blown powder techniques are now being widely explored to produce near net shape components for various applications in aerospace, defence, automotive, and medical implantation [1-4]. By consolidating metallic powders layer by layer, laser and electron beam-based AM processes have opened up a new paradigm in near-net-shape manufacturing high value components with topographically optimised geometries, without the need for expensive tooling or extensive machining. The static mechanical properties (yield, tensile strength and ductility) of Ti6Al4V AM components are already comparable to those made from traditional wrought processes (e.g. forging) [5]. However, parts produced by powderbased AM techniques still suffer from a poor surface finish and internal defects (Figure 1 (a), (b) and (c)) [6]. Without further machining and post-build treatments, such as hot isostatic pressing (HIPing), which adds additional cost this makes the quality of AM components currently insufficient for highly stressed applications that experience dynamic in-service loads (e.g. in aerospace). In addition, there are application driven aesthetic and functional requirements for surfaces: for example, a smooth surface with roughness $\mathrm{Ra}<1.0 \mu \mathrm{m}$ is often required in dental implants to prevent bacteria accumulation [7], as illustrated in Figure 1 (d).
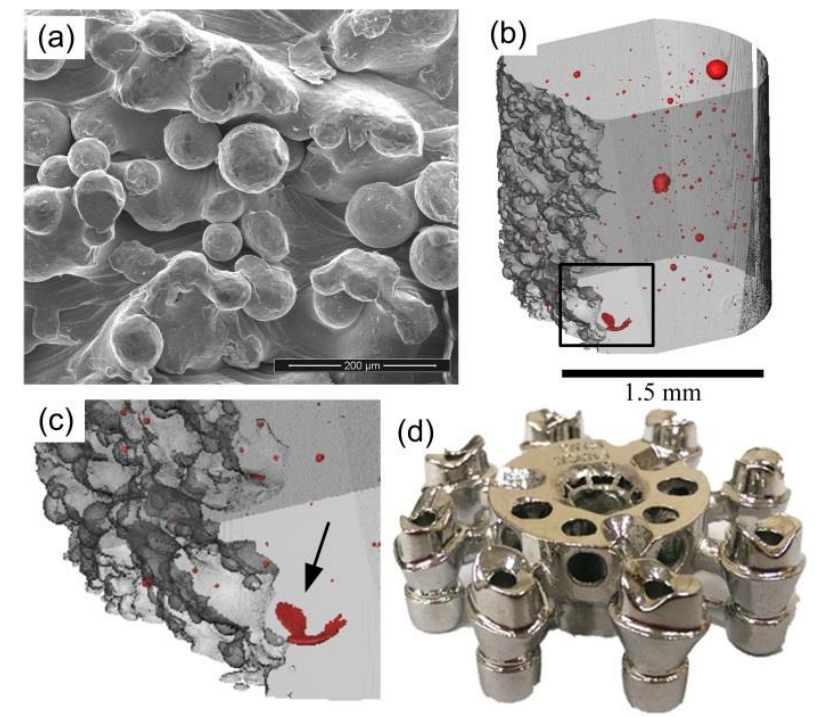

Figure 1 Example of the high surface roughness and typical subsurface defects found at the vertical build surface of an EBM powder bed Ti6Al4V sample; (a) SEM imaging of the as-built surface; (b) and (c) high resolution X-ray computed tomography (XCT) showing the surface with an intrusion defect (arrow) [6]; and (d) an electrochemically polished dental implant. 
Typically, a high microscopic roughness of $\mathrm{Ra}>15 \mu \mathrm{m}$ is obtained on AM parts produced by SLM, LMD and EBM [7-11], but a roughness level of $\mathrm{Ra}<0.8 \mu \mathrm{m}$ is needed in many applications to avoid premature fatigue failure induced by surface stress concentrations [12]. The roughness of a surface also varies considerably depending on its orientation within the build chamber. Generally the top surface of a powder bed AM part is the smoothest with the roughness mainly controlled by rippling from instability and surface tension effects in the melt pool tracks $[12,13]$. In comparison, the vertical surfaces of an AM part typically have a higher roughness due to partially melted powder particles sticking to the outer edge of the melt pool in the contour pass (Figure 1), which is often referred to as 'satellite formation' [15]. Finally, the highest roughness is seen with overhanging surfaces where steps in layer height become apparent, leading to a 'stair case' appearance [16]. To tackle this problem, efforts have been made to adjust the shape of the laser beam, optimise the scanning strategy, or reduce the scanning step size and layer height, but such measures tend to reduce productivity and improvements in the as-built surface roughness are still far from satisfactory $[10,15,17]$.

Currently, the most common solution to achieving an adequate surface finish in AM is through CNC (computer-numeric-control) machining, or mechanical polishing [1,2]. However, it is often impossible to machine, or mechanically polish, a complex AM build due to limited accessibility, particularly for internal surfaces. Although alternative abrasive and chemical methods are being investigated, these all suffer from additional problems such as a lack of precision and shadowing $[18,19]$. Therefore, it is important to explore more controlled approaches to achieve a satisfactory surface finish.

Laser polishing (LP) is an emerging technique that has shown potential to reduce the surface roughness of metal components [20-23]. It uses a laser beam to re-melt a thin surface layer and subsequently smooths the surface roughness by exploiting surface tension in the melt pool (Figure 2); i.e. it is most successful when the heat source is controlled to generate a high aspect ratio melt pool, in terms of width to depth. LP offers high flexibility and can potentially be used with a high process speed, but more importantly it can be precisely directed to locally 'engineer' surfaces, where required.

Heidrich et al. [24] have used laser polishing to successfully demonstrate the ability to reduce the roughness of ground glass surfaces to a level of Rms $<1 \mathrm{~nm}$, which is sufficient for some optical applications. In comparison, with H13 tool steel Hafiz et al. [25] have reported an 
$86.7 \%$ reduction in areal roughness from laser polishing. By using a continuous wave Nd:YAG laser, Kumstel and Kirsch [23] claim reductions in roughness of machined Ti6Al4V surfaces from $\mathrm{Ra}=1 \mu \mathrm{m}$ to $0.16 \mu \mathrm{m}$ and from $\mathrm{Ra}=1 \mu \mathrm{m}$ to $0.11 \mu \mathrm{m}$ with Inconel 718. More recent studies of laser polishing of additive manufactured surfaces have also shown positive results. For example, Marimuthu et al. [20] have obtained a roughness reduction of $76 \%$ on SLM Ti6Al4V surfaces and Gora et al [9] achieved an 85\% reduction with EBM Ti6Al4V components. Ma et al. [26] used a nanosecond pulse laser and successfully reduced the surface roughness by about $80 \%$ on two types of titanium alloy AM components. Bhaduri et al. [27] reported about a 94\% reduction in surface roughness by using laser polishing on a mesoscale 316L AM surface. By combing selective laser erosion with laser polishing, Yasa et al [28] have also obtained an improvement in the smoothness of SLM 316L stainless steel surfaces of $90 \%$. Laser polishing can also be incorporated in certain AM process, such as LMD, so that surfaces can be smoothed while the component is built, increasing access to internal cavities. Laser polishing thus has the potential to be highly beneficial for improving the functionality and performance of specialised AM components.

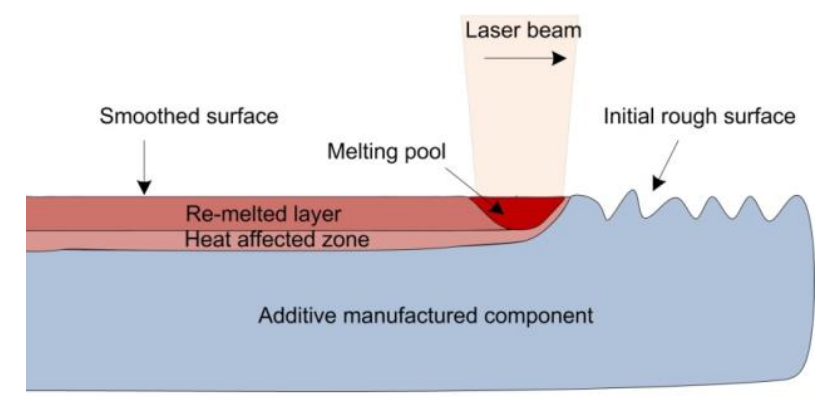

Figure 2 Schematic diagram of the laser polishing process.

Although very encouraging improvements in surface roughness have been achieved by laser polishing AM parts, to-date most of the literature has focused on process parameter optimisation and little has been published on the effect of re-melting and rapidly solidifying a thin surface layer on the local microstructure and residual stress state, and the subsequent mechanical properties of the subsurface region, which is often a critical site for failure initiation (e.g. by fatigue). In particular, for additive manufactured components used in aerospace applications, it is not only important to obtain smoother surfaces, but it is also essential to have full knowledge of any associated changes to the sub-surface microstructure to 'de-risk' new applications. To address this key issue, this study has used Ti6A14V EBM samples, built under standard conditions, as an example to systematically evaluate the influence of laser polishing on the sub-surface microstructure, defects, texture, and residual 
stresses caused by re-processing the surface of a typical powder-bed titanium AM component. In addition, we have also measured the improvement in surface roughness possible in more detail than previously, by obtaining data at multiple length scales.

\section{Materials and Experimental}

EBM AM samples, $30 \mathrm{~mm} \times 7 \mathrm{~mm} \times 50 \mathrm{~mm}(x, y, z)$, were built in an Arcam S12 EBM machine by GKN Aerospace, using standard recommended Arcam parameters and Ti6Al4V pre-alloyed plasma atomised powder feedstock, with a particle size distribution between 45 and $100 \mu \mathrm{m}$. Laser polishing was conducted on the larger vertical AM surfaces using an SPI redPOWER 100C system, based on a fibre laser with a wave length of $1070 \mathrm{~nm}$. The laser power was set at $100 \mathrm{~W}$, with a beam quality factor $\mathrm{M}^{2}<1.1$. The optimum process window developed for laser polishing with this system, in terms of improved smoothness while avoiding solidification cracking, is provided in Table 1 (further details will be discussed in a separate article). Namely, the laser beam was defocused to a spot size of $400 \mu \mathrm{m}$ in diameter and a scanning speed of $300 \mathrm{~mm} / \mathrm{min}$ was used with a $30 \mu \mathrm{m}$ line offset and a 'snaking' raster pattern. Argon gas was used to protect the surface from oxidation during LP processing. The surface roughness before and after laser polishing was measured by a Nanofocus $\mu$ Scan laser profilometer and at higher resolution by a Veeco Contour GT white light interferometer. To investigate the influence of laser polishing on the sub-surface material, both surface and cross sectional views were examined by scanning electron microscope (SEM), electron backscatter diffraction (EBSD) and transmission electron microscope (TEM). Hardness profiles from the re-melted layer to the base material were measured using an MTS-XP nano indenter with a Berkovich tip and $200 \mathrm{~nm}$ indentation depth. Site-specific TEM samples were produced using an FEI Quanta 3D dual beam focused ion beam (FIB) system.

Table 1 Laser processing conditions used in this study.

\begin{tabular}{lllll}
\hline Power & Speed & Spot Size & Line Spacing & Scanning Strategy \\
\hline $\mathbf{1 0 0} \mathbf{W}$ & $5 \mathrm{~mm} / \mathrm{s}$ & $400 \mu \mathrm{m}$ & $30 \mu \mathrm{m}$ & Snaking raster pattern \\
\hline
\end{tabular}

It is known that AM components contain subsurface porosity and defects [6], which play an important role in their mechanical properties (Figure 1). $1.8 \mathrm{~mm} \times 1.8 \mathrm{~mm} \times 5 \mathrm{~mm}$ samples were therefore machined out of the laser polished EBM vertical surfaces and examined in a Zeiss Micro high-resolution X-ray tomographic system at the Henry Moseley X-ray Imaging Facility, using an accelerating voltage of $80 \mathrm{kV}$ and $125 \mu \mathrm{A}$ current to achieve a voxel size of 
$1.2 \mu \mathrm{m}$. Any defects present were segmented and visualised using the software package FEI Avizo 9.1.

As a surface undergoes highly localised heating and rapid cooling during laser polishing, for fatigue critical applications it is of interest to understand how this affects the surface residual stresses. Residual stress depth profiles were, therefore, measured in both as-built laser

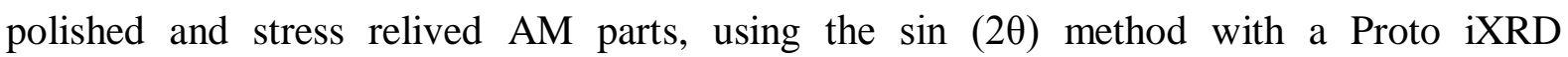
diffractometer. For depth profiling material removal was achieved by electropolishing using a Struers LectroPol machine, with a designated Struers A3 electrolyte. Stress relief was performed at $750{ }^{\circ} \mathrm{C}$ for 4 hours followed by furnace cooling, all under vacuum to avoid surface contamination.

\section{Results and Discussion}

\subsection{Surface Roughness Reduction}

Figure 3 shows an EBM sample with three small laser polished test regions produced on one of its vertical surfaces. As expected, prior to polishing such surfaces exhibited a rough appearance on the scale of the feedstock powder, due to the attachment of partially melted particles (Figure 1). At low magnification it was immediately apparent that following laser polishing there was a large improvement in surface quality, with the polished regions being significantly smoother and having a much more reflective appearance, compared to the asbuilt surface (Figure 3(c)). However, some longer range waviness could still be seen in the polished areas. This longer range deviation from planarity is inherited from the original asbuilt sample, as long range out of plane deviation cannot be removed by laser polishing with a small melt pool size. In Figure 3(d) the polished surface is shown at a higher magnification which, along with Figure 3(c), reveals that under optimum conditions there is minimal evidence of surface definition from individual tracks and that the remaining fine-scale roughness is mainly associated with metallurgical effects, including grain boundary grooving (due to surface tension) and very fine scale surface relief caused by the solid state $\beta \rightarrow$ $\alpha$ phase transformation (see below §3.3).

Figure 4 provides roughness measurements performed at different length scales. The laser profilometer had a spatial and height resolution of $2 \mu \mathrm{m}$ by $0.2 \mu \mathrm{m}$, respectively, and was able to acquire information from both rough as-built and polished surfaces (Figure 4 (a) \& (b)), while with polished surfaces the white light interferometer could achieve higher spatial 
and height resolution $(0.2 \mu \mathrm{m}$ by $0.1 \mathrm{~nm}$, respectively) (Figure 4 (d) \& (e)). Average areal roughness, $\mathrm{Sa}$, values measured by these techniques were used to evaluate the improvement in surface quality and are summarised in Table 2, where Sa represents the arithmetic mean of the absolute value of the height within the sampling area. The calculation was in compliance with ISO 25178 standard (Geometrical product specifications (GPS) - Surface texture). As demonstrated in Table 2, by applying laser polishing, when measured over a representative 2 $\mathrm{mm} \times 3 \mathrm{~mm}$ area, the Sa parameter reduced from $21.46 \mu \mathrm{m}$ to $5.5 \mu \mathrm{m}$; corresponding to a $75 \%$ reduction in roughness. This roughness level, measured after polishing, is competitive with the typical condition that can be expected from CNC machining [29]. It should also be remembered that the initial starting roughness is probably under measured because the laser probe cannot always 'see' to the root of deep narrow intrusions between powder particles (Figure 1 (c) and Figure 3 (a)).

To obtain a higher resolution with the white light interferometer the sampling area used was reduced to the submillimetre scale $(0.13 \mathrm{~mm} \times 0.17 \mathrm{~mm}$; Figure $4(\mathrm{~d}))$, and the 'roughness' recorded then dropped dramatically to $\mathrm{Sa}=0.51 \mu \mathrm{m}$. As this smaller sampling area became similar to the $\beta$ grain size, this suggests that the majority of short range roughness retained after laser polishing was related to surface relief between individual grains and grain boundary grooving generated during the solidification process.

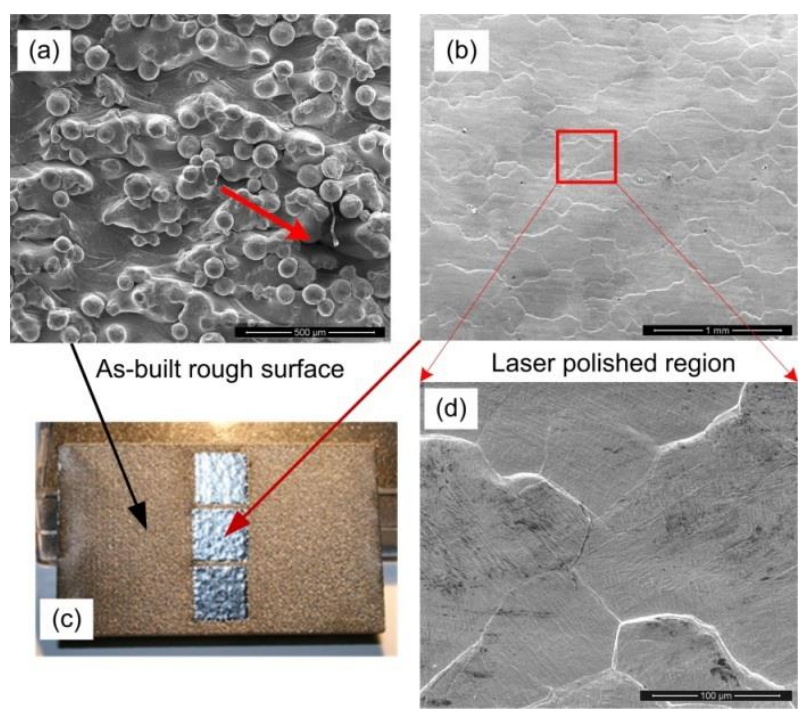

Figure 3 Unpolished and laser polished test regions, all obtained under optimised parameters, on the vertical side of an EBM sample; (a) SEM images of the unpolished surface, (b) SEM images of the polished surfaces, (c) unpolished and polished surfaces at a macro-scale, and (d) a magnified polished region (from the 'box' in (b)); The arrow in (a) highlights a deep local surface intrusion.

Table 2 Roughness ( $\mathrm{Sa}$ ) parameters measured from the EBM as-built vertical surfaces and laser polished areas, at different resolutions using a Nanofocus $\mu$ Scan laser profilometer and white light interferometer. 


\begin{tabular}{l|c|c|l}
\hline & Measured area & Areal roughness parameters $\boldsymbol{S a}$ & Technique \\
\hline EBM as-built & $2 \mathrm{~mm} \times 3 \mathrm{~mm}$ & $21.46 \mu \mathrm{m}$ & $\mu$ Scan \\
\hline \multirow{3}{*}{ Laser Polished } & $2 \mathrm{~mm} \times 3 \mathrm{~mm}$ & $5.50 \mu \mathrm{m}$ & $\mu$ Scan \\
\cline { 2 - 4 } & $0.65 \mathrm{~mm} \times 0.86 \mathrm{~mm}$ & $1.65 \mu \mathrm{m}$ & Interferometer \\
\cline { 2 - 4 } & $0.13 \mathrm{~mm} \times 0.17 \mathrm{~mm}$ & $0.51 \mu \mathrm{m}$ & Interferometer \\
\hline
\end{tabular}

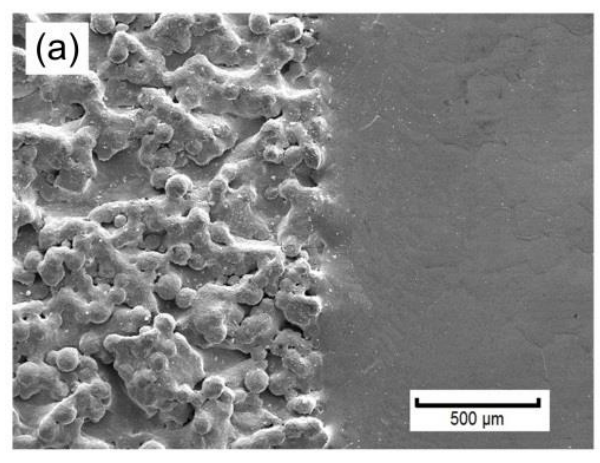

(c) (b)

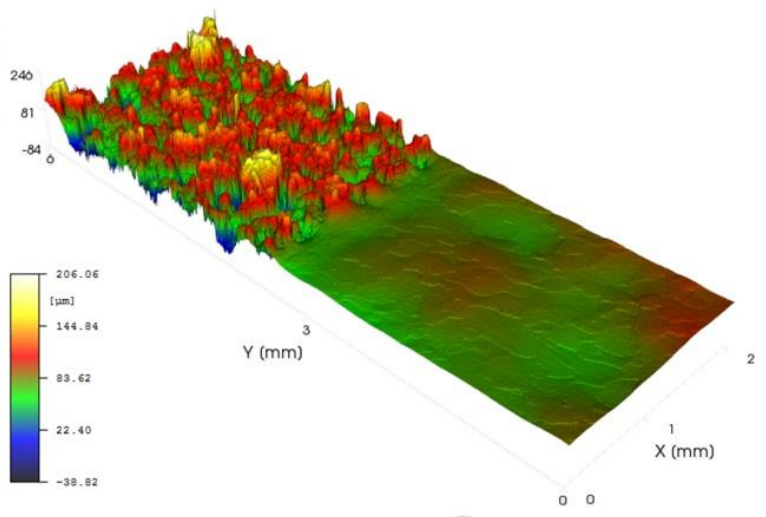

(d)
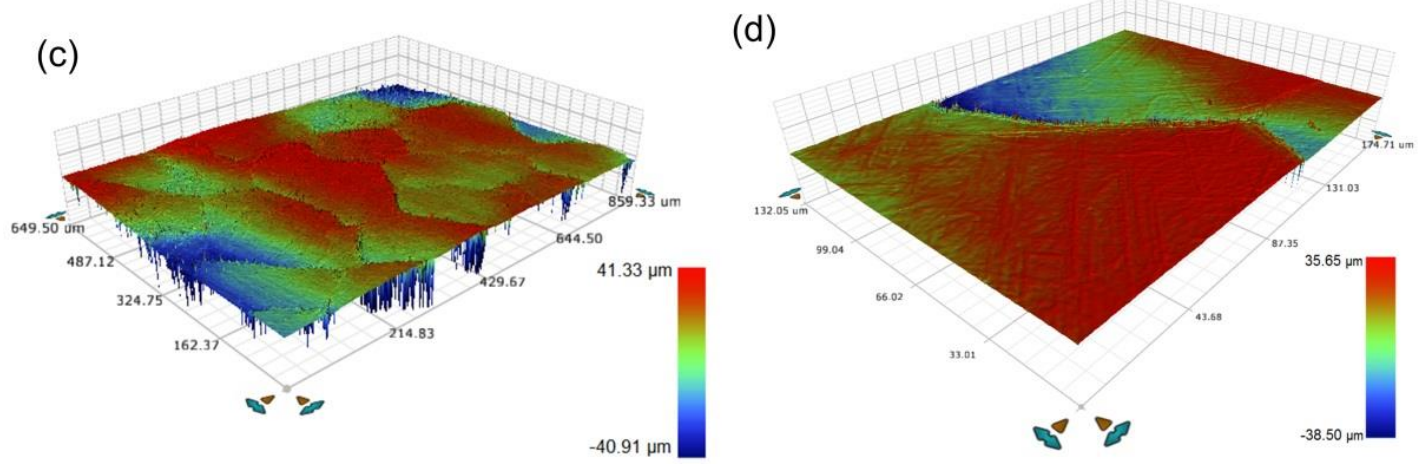

Figure 4 Roughness reduction by laser polishing measured by surface profiling at different scales: (a) an SEM image showing the contrast between the original and polished surfaces with; (b) the equivalent transition using the laser profilometer, with an area of $2 \mathrm{~mm} \times 6 \mathrm{~mm}$, (c) the LP surface measured over a $0.65 \mathrm{~mm} \times 0.86 \mathrm{~mm}$ area, and (d) measured over a $0.13 \mathrm{~mm} \times 0.17 \mathrm{~mm}$ area by white light interferometery.

\subsection{Grain Structure and Texture of the LP Layer}

In $\alpha-\beta$ titanium alloys, analysis of the grain structure formed during solidification is complicated by the fact that solidification occurs with the growth of (bcc) $\beta$ as the primary phase, which then transforms on cooling to a complex lamellar $\alpha+\beta$, or $\alpha$, microstructure (see $\S 3.3$ below). This makes direct analysis of the original solidification texture impossible in room temperature samples, although it can be reconstructed from EBSD data using a procedure based on the Burgers orientation relationship (BOR) between the two phases, which is given by:

$$
\{100\} \beta / /\{0002\} \alpha ;<111>\beta / /<11 \overline{2} 0>\alpha
$$


Full details of the $\beta$ phase reconstruction method that has been employed in this study can be found in the work from Davies and Wynne [28, 29].

Figure 5 (a) shows an EBSD orientation map measured from the $\mathrm{X}-\mathrm{Y}$ plane normal to the build direction, $\mathrm{Z}$, of the $\alpha$ phase just below the laser polished surface. The map was taken on a cross-sectional view vertical to the AM building direction. The two arrows on the top of the image indicate the 'snake raster' laser scanning direction during polishing. The map can be roughly divided into (i) the re-melted layer, (ii) a heat affected zone (HAZ), and (iii) the unaffected base material, although it is difficult to accurately identify the fusion boundary in titanium alloys as there is not a clear metallurgical transition between the parent and melted material due to a lack of solute partitioning. As the $\beta$-transus temperature of Ti6Al4V is about $980{ }^{\circ} \mathrm{C}$, while the melting point is $1600{ }^{\circ} \mathrm{C}$ [32], the upper part of the HAZ has a similar transformation microstructure to the fusion zone; i.e. all the material that was reheated to above the $\beta$-transus temperature (including the fusion zone) has fully transformed to a much finer ' $\alpha$ ' microstructure on cooling, and this has occurred to a depth of about $250 \mu \mathrm{m}$, whereas the melt depth was roughly $180 \mu \mathrm{m}$ from the top surface. A narrow transition region can also be observed in the lower part of the HAZ where the material changes from a fully transformed finer ' $\alpha$ ' microstructure to a partially transformed ' $\alpha$ ', containing residual primary $\alpha$. In this region the volume fraction of primary $\alpha$ increases with depth as the peak temperature falls back to that of the parent substrate material (see $\S 3.3$ below).

In the $\alpha$ phase orientation map in Figure 5 (a) a memory of the parent $\beta$ grains can be seen in the re-melted polished region, from the local texture variation. However, the prior $\beta$ grain structure is much more apparent in the reconstructed $\beta$ map, shown in Figure 6(a). With Ti6Al4V components built by the Arcam EBM machine it has previously been demonstrated [33], that the bulk of a section in the hatching region generally contains a coarse columnar primary $\beta$ grain structure with a $<001>/ / Z$ fibre texture aligned with the build direction $(Z)$, although the fibre texture often shows evidence of not being fully random around the build direction and can have cube reinforcement. This texture develops because the steep thermal gradient at the solidification front in the EBM process favours columnar growth and $\langle 001\rangle$ is the preferred growth direction in cubic metals. With a rapidly moving, elongated, shallow melt pool, after multiple layers it has been shown that this preferred growth direction is preferentially selected to align with build direction, because on average it gives the fastest 
growth rate at the solidification front when there is a forward and backward motion of the melt pool [32].

In contrast, close to the vertical face of a EBM built part an outer skin layer of finer columnar grains is formed that nucleated from partially melted powder in the bed and grew curving inwards and upwards following the maximum thermal gradient at (i.e. normal to) the melt pool surface of the contour pass. The finer grained outer skin layer is typically about the half the width of the melt pool size for the first contour pass and repeated contour passes also tend to create a different coarser z-aligned columnar structure within the inner side of the contour tracks that and extends inwards by $<0.8 \mathrm{~mm}$ (see ref [33]). In Figure 6 (a) it is apparent that grains in the re-melted layer have a different crystallographic orientation that is closer to $<011>/ / Z$ while, as expected, the preferred orientation of grains in the substrate is predominantly $<001>/ / Z$. A finer band of grains can also be seen between the re-melted region and substrate, coinciding with the HAZ transition region, which is probably a remnant of the edge of the skin layer produced by the EBM processes. The re-solidified grain structure in the surface layer melted by laser polishing has clearly grown back epitaxially from the substrate, leading to a relatively coarse columnar grain structure (given the high cooling rate) that is slightly tilted over in the direction of melt pool travel (i.e. towards the right in Figure 6 (a)). It is not surprising that in laser polishing columnar growth with epitaxial nucleation is observed on solidification of the re-melted surface layer, given the steep thermal gradient that will be present at the solid liquid interface. As has been widely reported, there is also a strong tendency for similar grain structures to develop in AM with a Ti6Al4V alloy, owing to its low level of solute partitioning, which makes it difficult to obtain a significant constitution undercooling at the growth front [33].

The pole figures in Figure 6 (b) and (c) are not reliable for describing textures owing to the low number of grains sampled, but nevertheless show the expected trend in that the substrate material suggests a close to $<001>/ / Z$ cube texture and in the re-melted layer the grains have reoriented because of the change in solidification direction to close to $<110>/ / Z$. This new growth direction coincides with a $<001>$ direction being perpendicular to the rear of the tilted melt pool solid/liquid surface when it travelled from left to right across the surface of the vertical side of the AM build (i.e. normal to the original melt pool travel orientation when the part was built). 
The $\alpha$ textures in the pole figures in Figure 5 (b) and (c), are relatively weak. For the substrate material, this occurs because when there is little variant section the transformation texture develops from the $\beta$ parent fibre texture will be diluted by the $12 \alpha$ orientations that are possible within each parent grain from the Burger's relationship. In contrast, in the remelted layer there is a stronger <1000> component aligned with $\mathrm{X}$, the laser travel direction. Owing to poor statistics, this observation should not be over interpreted, but may indicate a preferred $\alpha$ variant orientation caused by residual stresses developing within the laser polished region during the $\beta \rightarrow$ ' $\alpha$ ' phase transformation.
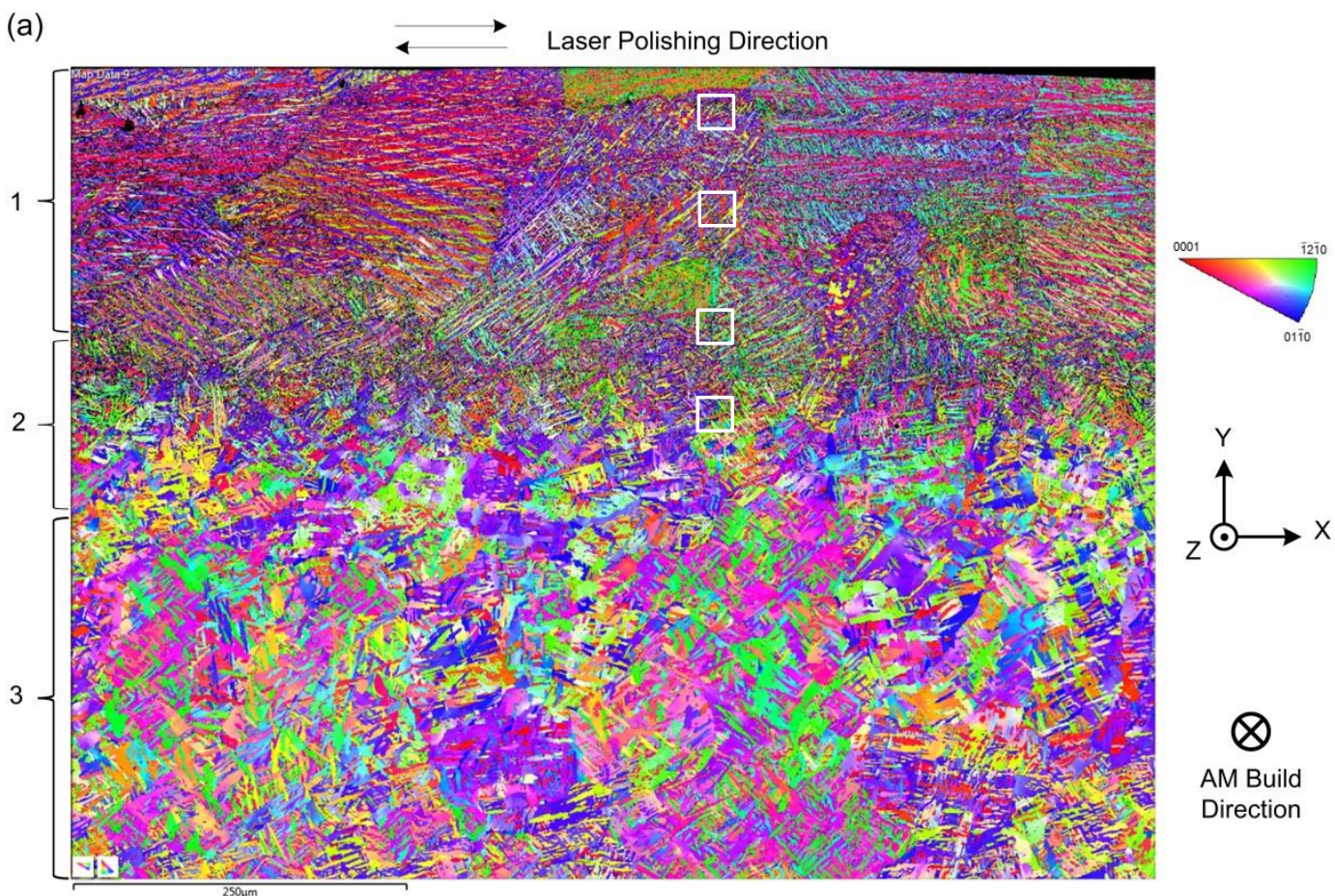

1. Re-melted region; 2. Heat affected zone; 3 . AM base

(b)
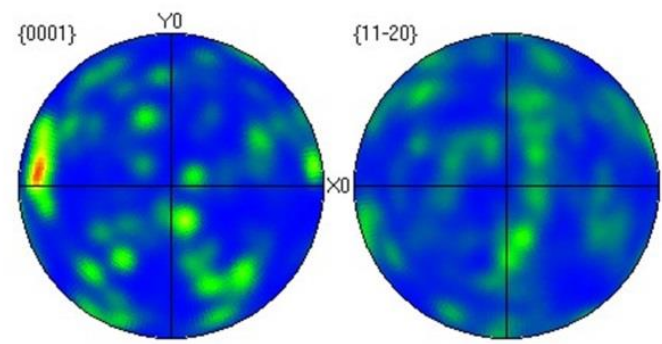

(c)
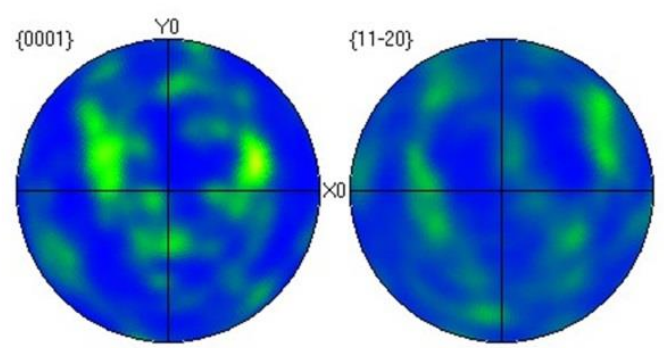

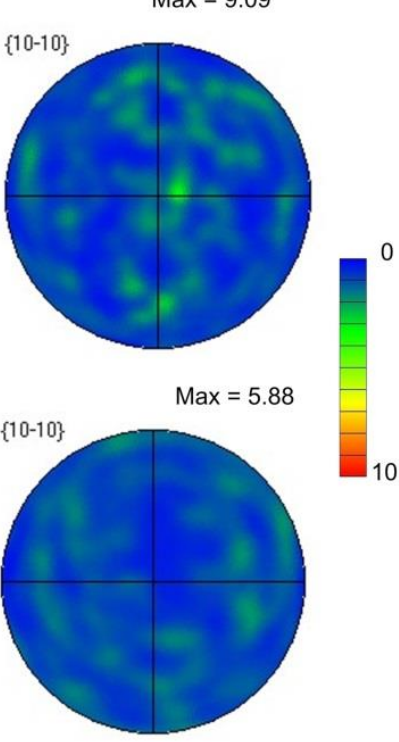

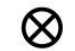

AM Build

Direction 
Figure 5 (a) $\alpha$ phase EBSD map from a cross section through the LP surface with the associated texture shown as standard pole figures; (b) the LP melted layer and (c) from the substrate region. The IPF colouring is relative to the build direction, $\mathrm{Z}$, and in the pole figures the orthogonal raster directions are $\mathrm{X}$ and $\mathrm{Y}$. The white boxes in (a) indicate the positons of high resolution SEM images in Figure 7.

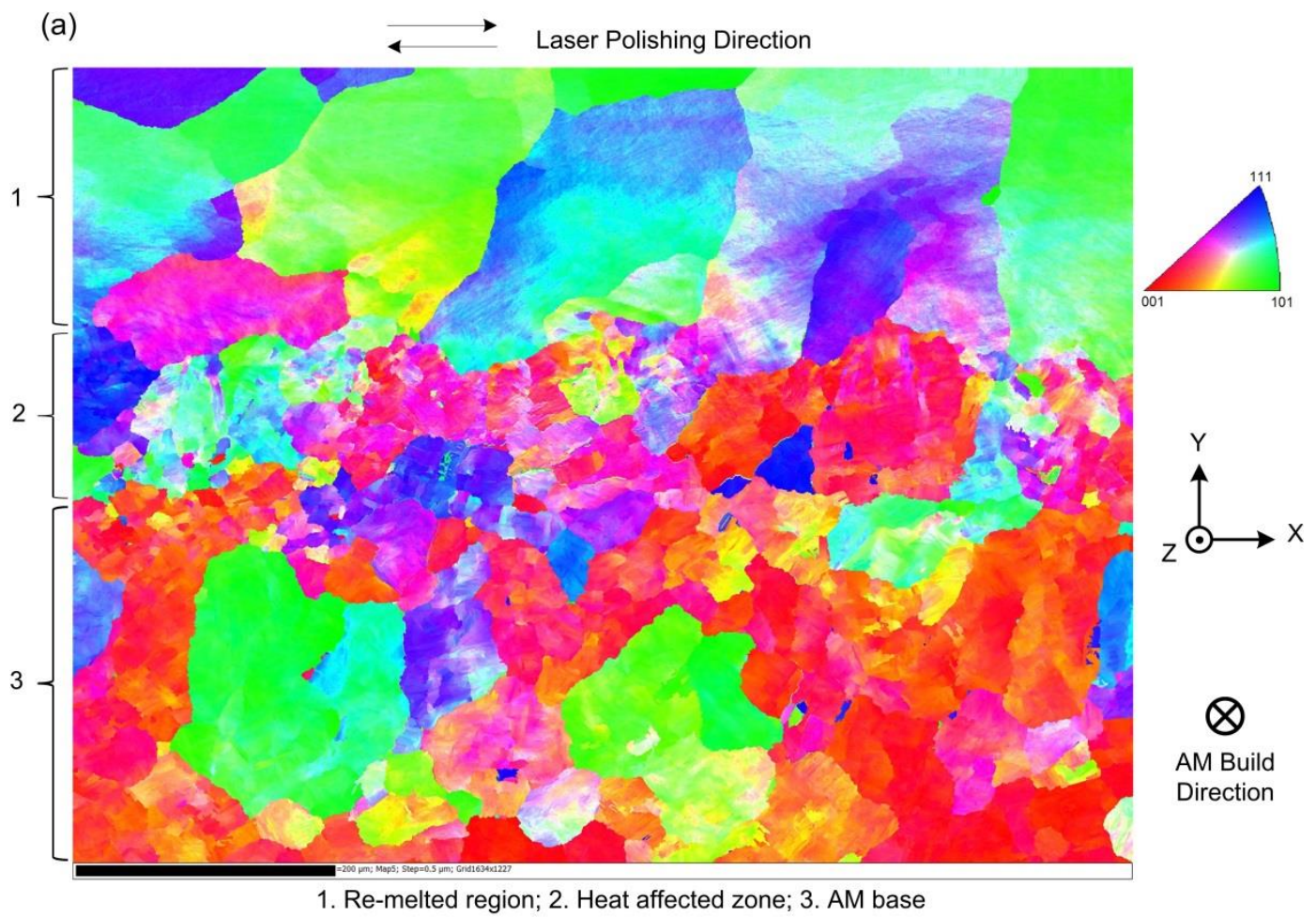

(b)
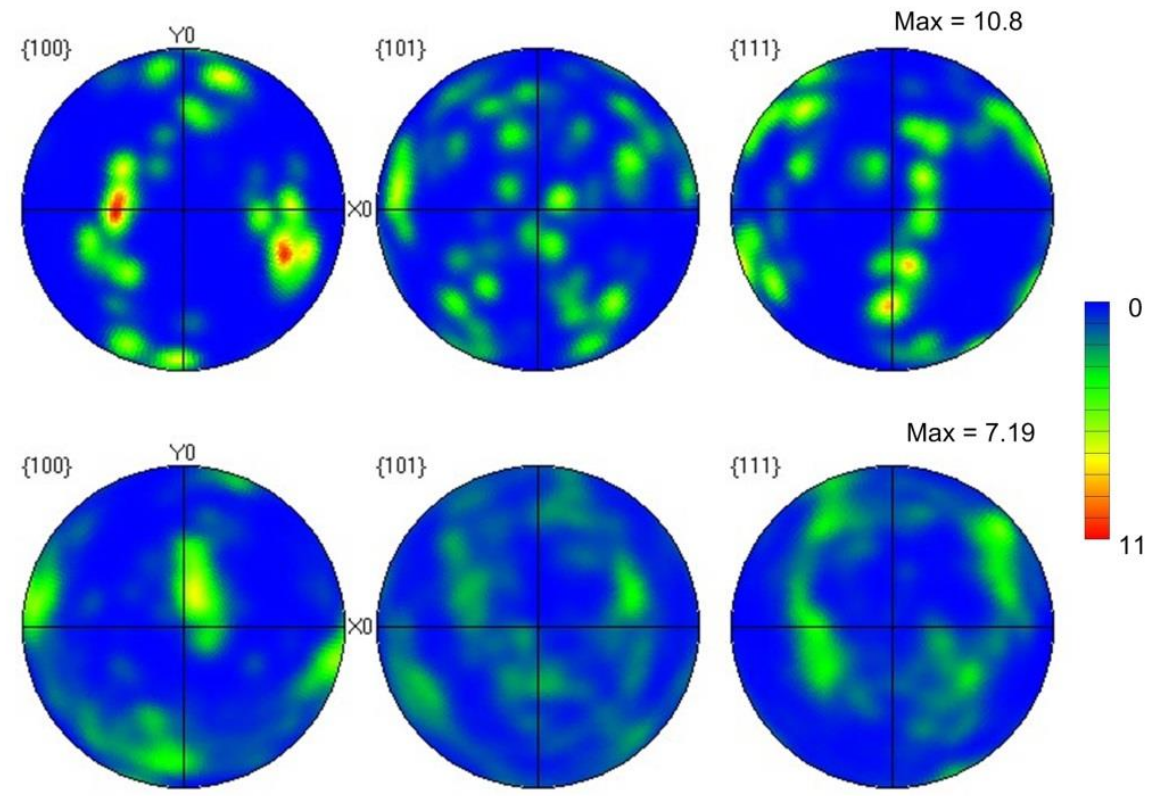

Figure 6 (a) reconstructed parent $\beta$ phase IPF orientation map, obtained from the EBSD map in Figure 5, showing in cross section the LP surface region and the transition to the base material. Pole figures of the associated reconstructed $\beta$ textures are provided in (b) for the re-melted region and (c) the AM base material. IPF colouring is relative to the build direction, $\mathrm{Z}$, and in the pole figures the sample orthogonal raster directions are $\mathrm{X}$ and $\mathrm{Y}$.

\subsection{Transformation of Microstructures}


Perhaps more important than a subtle difference in surface texture, to the mechanical performance of a laser polished component, are any significant changes in the $\alpha+\beta$ transformation microstructure. In electron beam melting with an Arcam machine, the powder bed is pre-heated between adding each layer using a rapidly scanned defocused beam to maintain the bed temperature at around $730{ }^{\circ} \mathrm{C}$, so that the thermal gradients experienced during the build are reduced [3]. This high build temperature can soak the component for several hours while it is being built, leading to a more homogeneous microstructure and low residual stresses. In the EBM process this normally results in a fine Widmanstätten $\alpha$ microstructure, which generally exhibits a certain degree of spheroidization of the retained $\beta$, owing to the high build temperature and long build times [34].

Figure 7 provides a series of high resolution SEM images as a function of depth through the laser polished re-melted layer and HAZ at different magnifications. In Figure 7 (a) an electron backscatter image is also shown of the actual polished surface. Surface relief is evident, which was detected by the white light interferometer in Figure 7 (d), and suggests a displacive reaction. At lower magnification the images also suggest a fine martensitic microstructure has been generated by the high cooling rate in the laser polishing process within the upper region below the surface that was heated fully above the $\beta$ transus temperature (including the re-melted layer). However, when the metallographically polished section is viewed at a higher magnification by back scattered imaging, in Figure 7 (b), it can be observed to contain a thin layer of $\beta$ between the $\alpha$ lath boundaries (Figure 7 (c)). From the lighter $\mathrm{Z}$ contrast in the images it is also clear that the $\beta$ phase is enriched in vanadium. Figure 8 further shows TEM images of the same region, which indicates that an exceptionally fine $\alpha+\beta$ structure is found in the laser melted region and, although a very thin layer of $\beta$ is clearly present, the $\alpha$ lath space is in the nanometre range. It is therefore debatable as to if this microstructure formed first as a martensitic structure, and was subsequently tempered by the thermal field from overlapping polishing tracks, or formed directly as a very fine Widmanstätten microstructure.

Although a relatively large spot size is used in laser polishing $(0.4 \mathrm{~mm})$, as the substrate is cold and the power is controlled so a shallow wide melt pool geometry is produced, there will be a higher thermal gradient and cooling rate compared to in an EBM process, and equally no long term thermal exposure. The conditions are thus more similar to SLM [1], which generally uses a cold bed, and the melted and $\beta$ annealed HAZ region during laser polishing 
must have therefore originally experienced a cooling rate substantially above $400{ }^{\circ} \mathrm{C} \mathrm{s}^{-1}$, which would be expected to produce a fully martensitic microstructure [35]. The results above thus suggest that the $\alpha^{\prime}$ martensite microstructure that initially formed during the first laser polishing pass must have subsequently decomposed to produce a very fine $\alpha+\beta$ lamellae structure, or a 'tempered' martensitic microstructure. A similar phenomenon has been reported by $\mathrm{Xu}$ et al [36], who has investigated in-situ martensite decomposition during selective laser melting.

As mentioned above, the upper part of the HAZ below the re-melted layer will be fully reheated above the $\beta$ transus temperature, so that the full $\beta \rightarrow \alpha^{\prime}$ phase transformation will occur below the fusion line down to the depth of the $\beta$-transus isotherm (i.e. about $980{ }^{\circ} \mathrm{C}$ ). In this study, a similar very fine $\alpha+\beta$ lamellae structure (shown in Figure 7 (b)) was therefore observed below the melt pool to a depth of $300 \mu \mathrm{m}$ from the laser polished surface.
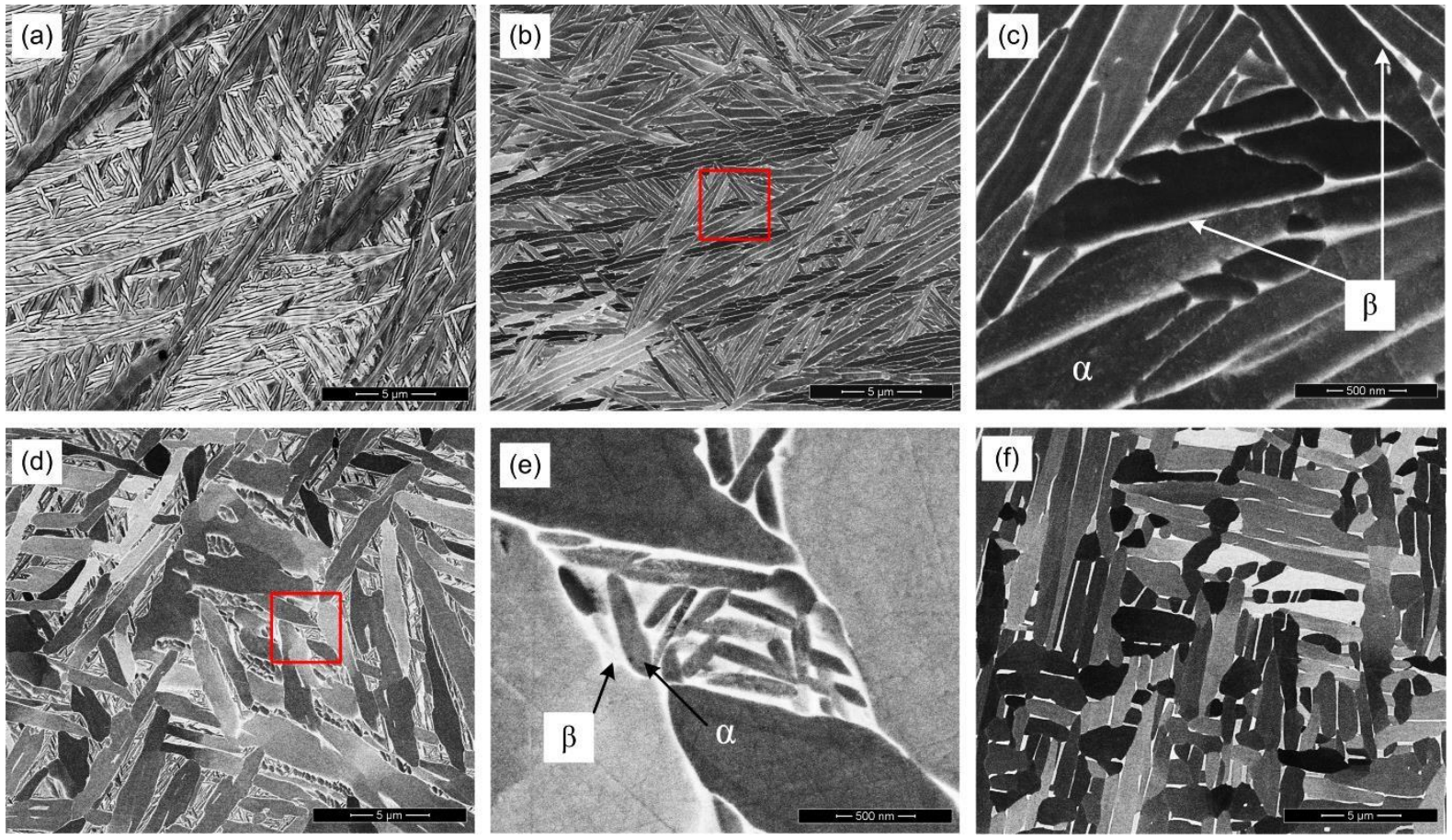

Figure 7 Transformation microstructures seen in the laser polished EBM samples at different depths below the surface: (a) an image looking down on the top surface; (b) and (c) cross section views from the re-melted layer;

(d) and (e) from the heat affected zone transition region; and (f) the AM parent material.

Further below the surface in the HAZ transition region, where the peak temperature reached during LP was below the $\beta$ transus, a narrow partially transformed region was observed, again consisting of fine $\alpha+\beta$ lamellae regions, transformed from the incompletely reformed $\beta$ phase, combined with retained, relatively larger, primary $\alpha$ laths inherited from the EBM substrate material (shown in Figure 7 (d) and (e)). This mixed partially transformed 
microstructure existed in the depth range of about $350-450 \mu \mathrm{m}$, but the volume fraction of the retained primary $\alpha$ laths increased with depth due to the falling peak temperature further below the heat source. Again, it was difficult to tell if the fine secondary $\alpha$ formed originally by a diffusional or martensitic reaction, but given the high cooling rate expected it would more likely be the latter. Below $\sim 500 \mu \mathrm{m}$ depth of the substrate material remained unaffected by the laser polishing process and had the typical Widmanstätten structure present in the EBM material (Figure 7 (f)).

To confirm these observations, XRD was also performed on the top surface of LP region and compared with results from the as-built EBM substrate material using a Philips X'Pert system. Despite clear evidence of surface relief from a displacive transformation (e.g. Figure 4 (d)) the diffraction (Figure 9 (a)) spectrum confirmed that the surface of the laser polished region contained both hexagonal $\alpha$ and cubic $\beta$ phases. However, when compared with the substrate material (Figure 9 (b)) the integrated peak area for the $\beta$ phase was over three times that of the laser polished region, suggesting that the equilibrium phase fraction and full partitioning of vanadium and aluminium had not been achieved in the laser polished sample, owing to the shorter thermal exposure.
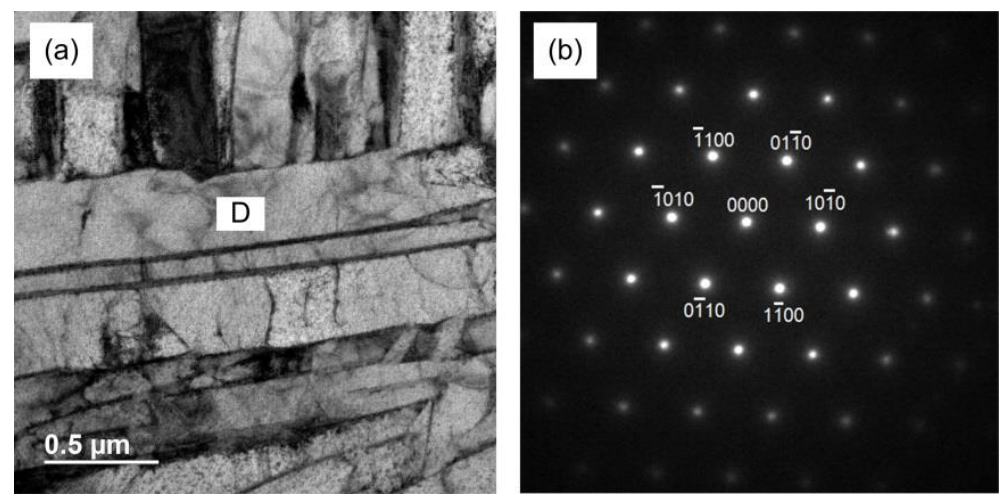

Figure 8 (a) TEM image of the very fine $\alpha-\beta$ transformation microstructure seen in the re-melted region and (b) associated diffraction pattern from the $\alpha$ phase.

In addition, further down in the HAZ small regions of transformed $\beta$ were identified that contained exceptionally fine secondary $\alpha$ plates that had a more martensitic appearance (Figure 10). This behaviour is consistent with the above interpretation, as the temperature reached by reheating from overlap of polishing passes would diminish with depth, leaving deeper regions less likely to be tempered by subsequent beam passes. 


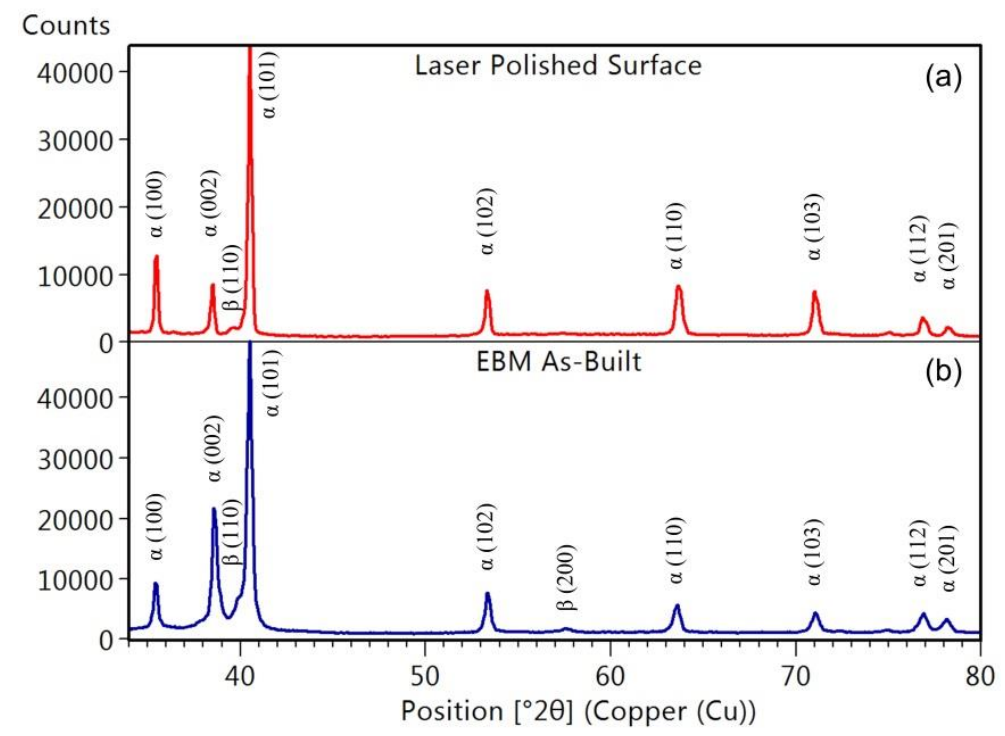

Figure 9 XRD spectrum from (a) the laser polished surface and (b) the standard EBM substrate.
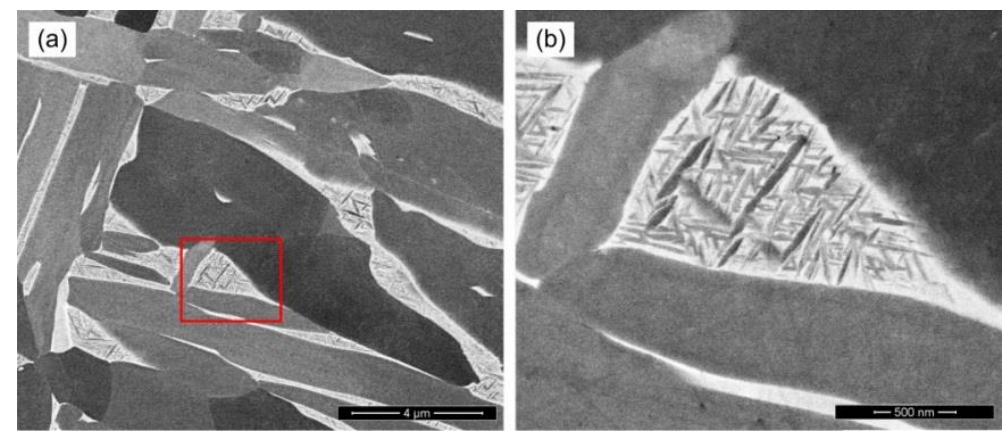

Figure 10 Examples of small transformed regions found near the base of the HAZ.

\subsection{Subsurface Micro-hardness Behaviour}

As the LP surface region probably consisted of decomposed martensite, it was expected that the very fine $\alpha+\beta$ microstructure within the laser affected layer might increase the subsurface yield strength. The hardness level below a LP surface was thus mapped with depth using an equal-spaced $5 \times 60$ matrix of nano-indentation tests, with a step size of $5 \mu \mathrm{m}$ and the average results measured at each depth positon have been plotted in Figure 11. This data suggests that there has only been a modest increase in the hardness of the LP surface layer by a maximum of about $15 \%$, as a result of laser polishing. This relatively small increase has occurred because, unlike in steel, the martensite transformation in titanium does not result in as large a hardness increase [32]. In addition, although a slightly harder surface layer could potentially be an extra risk factor for the in-service life of a laser polished component this could be relatively easily rectified be a subsequent stress-relief heat treatment. As will be shown below ( $\$ 3.5)$, it would be sensible in any case to conduct a stress relief, or combine 
this with a HIPing, operation after laser polishing, because of the increase in subsurface residual stresses caused by the polishing process.

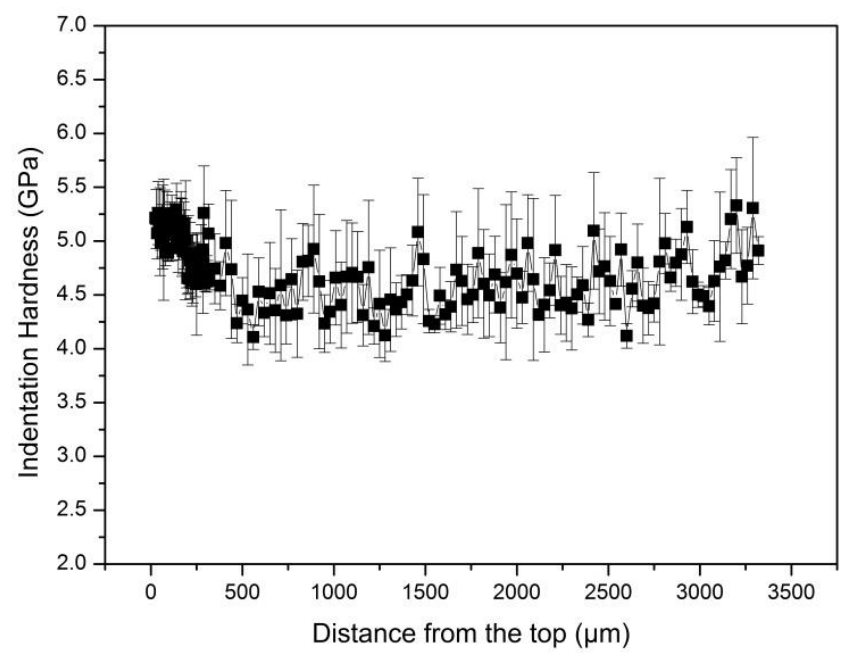

Figure 11 Hardness profile from the LP region to the AM base by nano-indentation.

\subsection{Residual Stress Measurements}

The strong possibility of undesirable residual stresses being generated by the laser polishing process was investigated by X-ray diffraction using the $\sin (2 \theta)$ method [37]. Figure 12 (a) compares residual stress depth profiles measured below a laser polished surface to that of the same surface prior to polishing from the original EBM sample. With the as-built sample, measurements were made in two perpendicular directions, parallel to the build direction and layer plane, respectively, but it can be noted that virtually no residual stresses were detected irrespective of the orientation. In comparison, after laser polishing a large near-surface tensile stress of $580 \mathrm{MPa}$ was measured parallel to the scanning direction $\left(0^{\circ}\right)$ with a lower stress in the transverse direction of $325 \mathrm{MPa}\left(90^{\circ}\right)$. However, the surface stresses then rapidly reduced to zero at a depth of approximately $1 \mathrm{~mm}$. It is not surprising that large tensile residual stresses are generated in a laser polishing process that involves surface heating a cold substrate with a small moving heat source [38]. This will naturally occur due to a compressive plastic misfit being formed by relaxation of the thermal stresses generated by the local volume expansion under the heat source, through melting and the low flow stress of the alloy at high temperatures. As cooling occurs, behind the moving heat source, this creates a tensile misfit that becomes more difficult to relax as the material becomes stronger with reducing temperature. It is also expected that the residual stresses will be larger parallel to the beam path owing to the elongated nature of the thermal field in the direction of travel of the heat source. Similar effects are typically seen in welding and have been widely reported [39]. 
Encouragingly, following a conventional stress relief anneal under vacuum of $750{ }^{\circ} \mathrm{C}$ for 4 hours, the subsurface tensile residual stresses in the LP sample were found to relax to near zero, as shown in Figure 12 (b). Full relaxation of the subsurface residual stresses following heat treatment can be attributed to their shallow depth, which means there is a minimal triaxial (normal) component and their relaxation by dislocation creep will therefore be relatively rapid at elevated temperatures.
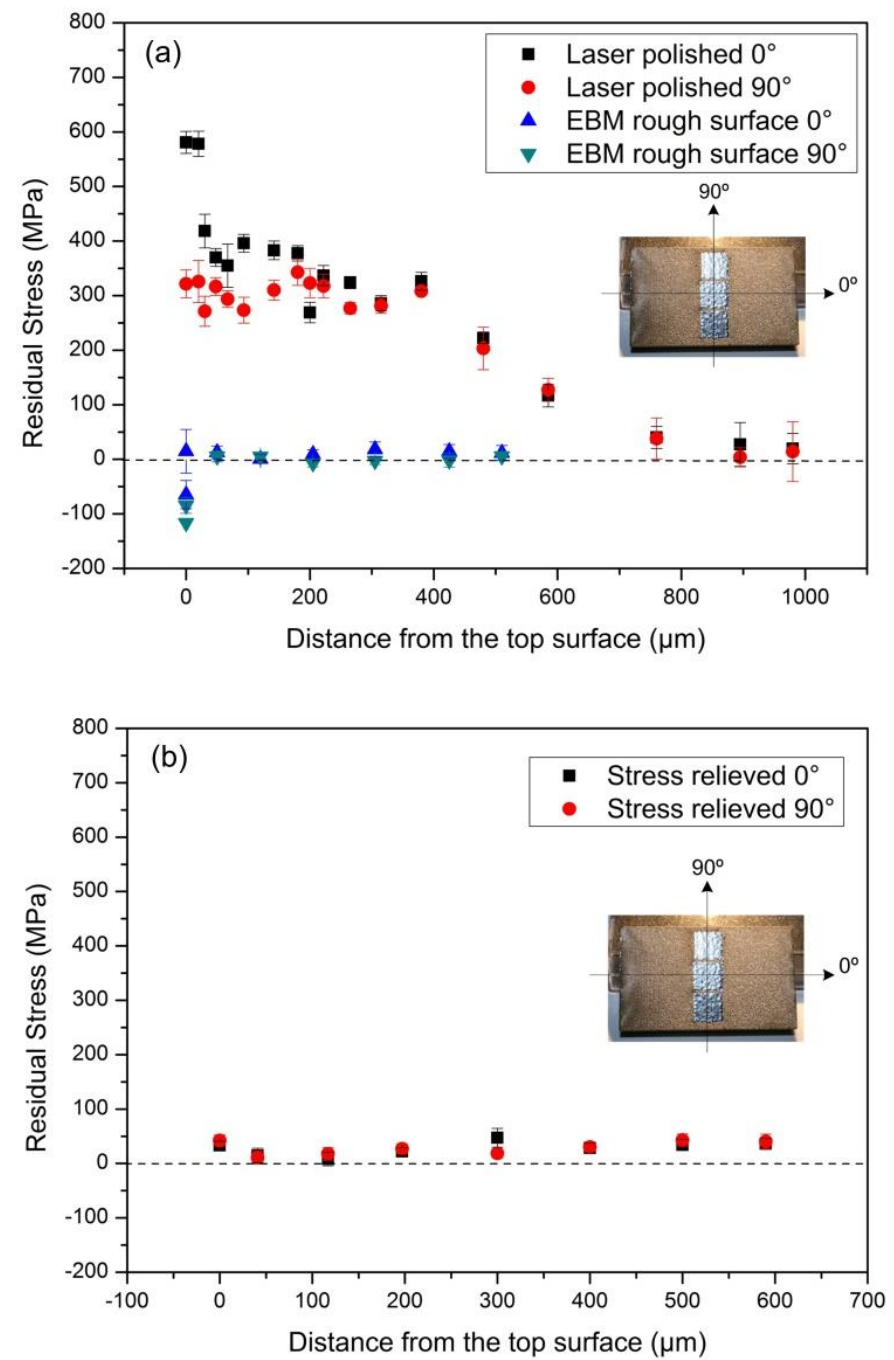

Figure 12 Residual stress depth profiles below a vertical build surface obtained from (a) an EBM as-built sample and its laser polished equivalent and (b) a laser polished sample after a stress relief heat treatment.

\subsection{X-Ray Tomography Results}

Like other AM processes, EBM can give rise to defects such as gas and lack of fusion porosity, which tend to be concentrated at the edge of the hatch region [6]. With parts built with the Arcam machine, within the contour region the pore density is typically low, although sharp surface intrusions can be created between un-fused powder at the melt pool boundaries 
in the contour pass between added layers (e.g. Figure 1 (c)) [6]. It is therefore of interest to investigate whether the laser polishing process can reduce such severe stress concentrations by re-melting the surface. Figure 13 shows a high resolution X-ray tomography 3D reconstruction of a typical surface region taken from the laser polished sample. The result suggests that in the region analysed the re-melted layer had no surface connected cracks, or remaining intrusions; i.e. the highly damaging intrusion defects shown in Figure 1 (b) and (c) were fully eliminated and no new ones were introduced by the laser polishing process. The morphology and size distribution of the pores in both AM base and LP region are compared statistically in Figure 14. Although it might be expected that re-melting the surface would cause a reduction in gas pores, by allowing a further opportunity for bubbles to escape from the melt pool, the morphology and geometric features of the gas porosity after laser polishing appeared comparable to that in the original AM base material in the same location (Figure 14).

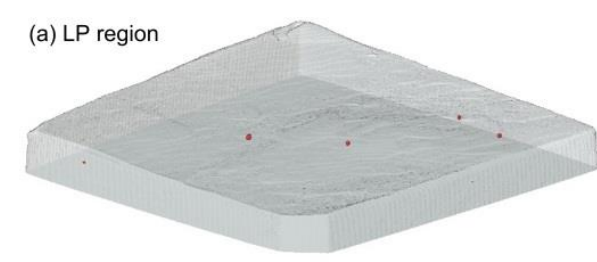

(b) AM base

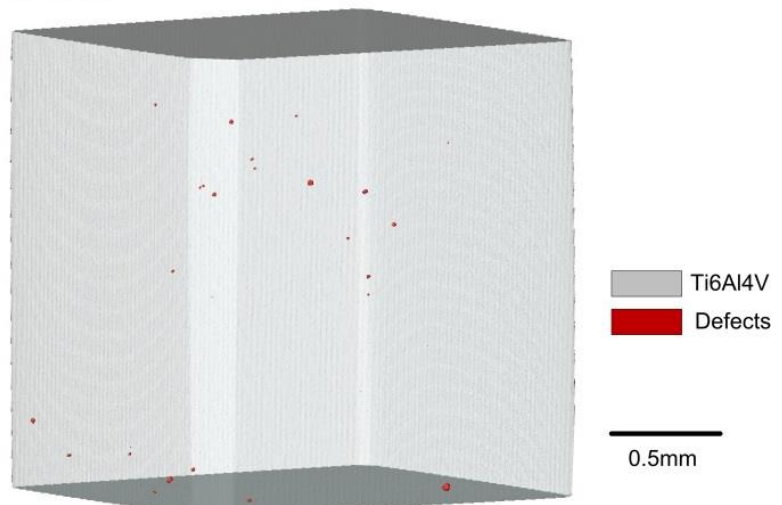

Figure 13 X-ray tomography results from the subsurface region of the laser polished sample: (a) LP region and (b) AM base.

Finally, as a note of caution it should be remembered that the contour pass already has a very low pore density in the EBM process [6] and this result is not fully conclusive as the small sample size used in this study necessary to achieve a high enough resolution (i.e. $1.2 \mu \mathrm{m}$ voxel size) to detect small pores was not sufficient to be statistically reliable. However, SEM imaging over larger areas (e.g. Figure 3 (b)) provided more confidence in the results, in that 
for the optimum process conditions investigated no surface breaking defects were observed in any of the laser polished samples.
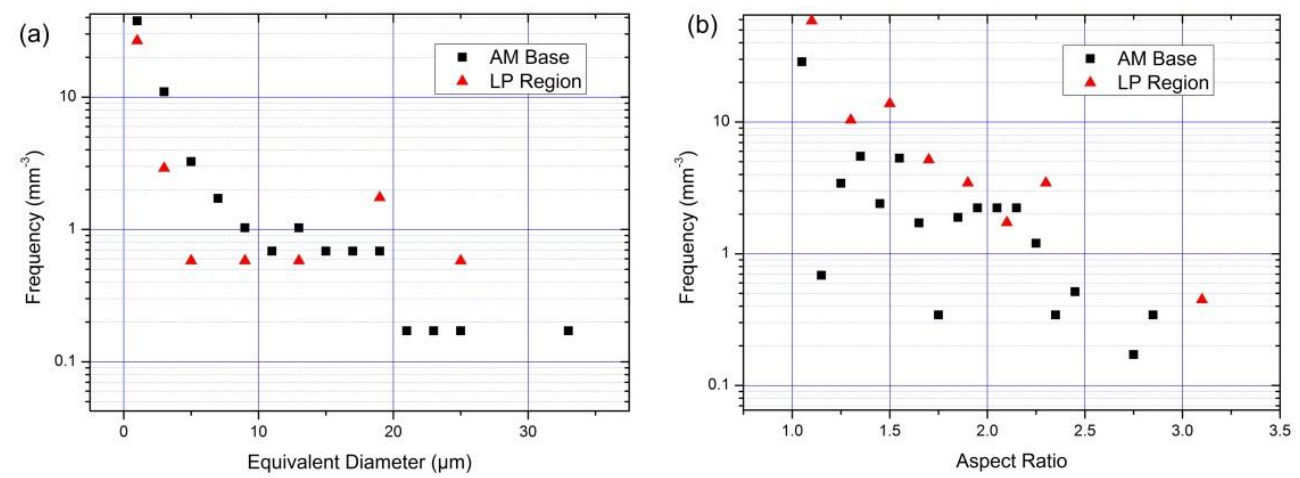

Figure 14 Comparison of the statistical analysis of pores from the AM sample contour pass and LP surface region: (a) equivalent diameter and (b) aspect ratio distributions.

\section{Conclusions}

It has been demonstrated that laser polishing can be successfully applied to EBM Ti6Al4V components and greatly reduces their high surface roughness. However, the laser polishing process can have a substantial effect on the near surface microstructure and residual stress state.

- Laser polishing reduced the surface roughness of an EBM component by over $75 \%$, when measured at the mm scale, but achieved a roughness level of only $\mathrm{Sa}=0.51 \mu \mathrm{m}$ when measured at the micro-scale. This improvement is highly comparable with that of mechanically polished or machined surfaces. In addition, laser polishing also removes high stress concentrations arising from surface intrusions formed during the AM build, without loss of material.

- The thin $(200 \mu \mathrm{m}$ deep) surface layer re-melted during laser polishing exhibited a different grain structure and a re-orientated texture relative to the AM substrate. In the re-melted layer columnar grains regrow epitaxially back from the substrate towards the melted surface, with a different preferred growth direction. This could be related to the change in orientation of the melt pool surface and beam scanning direction, relative to that in the original AM build.

- A HAZ was found to extend into the material to a depth of $\sim 450 \mu \mathrm{m}$. This consisted of an approximately $300 \mu \mathrm{m}$ deep sub-surface layer that was fully $\beta$ annealed, as well 
as a partially transformed transition layer. The fully transformed region probably underwent a martensitic transformation on cooling, followed by in-situ decomposition to a very fine $\alpha+\beta$ lamellae structure during subsequent beam passes. The partially transformed transition layer contained a diminishing volume fraction of secondary $\alpha$ and an increasing volume fraction of coarser primary alpha laths with depth.

- As a result of the much finer subsurface microstructure, there was a small increase in hardness to the same depth as the HAZ generated by laser polishing.

- With the parameters used in this study, laser polishing induced a high level (up to 580 $\mathrm{MPa}$ ) of tensile residual stresses in the component's surface, which decayed rapidly with depth. However, the residual stresses could be fully relaxed relatively easily by performing a standard stress relief heat treatment.

- When processed under optimum conditions the laser polished layer was found to contain no surface cracks, or other flaws, but had a similar low gas pore population to the contour region of the AM base material.

\section{Acknowledgement}

The authors would like to acknowledge sponsorship from the UK Engineering and Physical Sciences Research Council through the Centre for Innovative Manufacturing in Laser-Based Production Processes (EP/K030884/1), together with additional support from SPI Lasers UK Ltd and Renishaw plc.

\section{Reference:}

[1] L.E. Murr, E. Martinez, K.N. Amato, S.M. Gaytan, J. Hernandez, D.A. Ramirez, P.W. Shindo, F. Medina, R.B. Wicker, Fabrication of Metal and Alloy Components by Additive Manufacturing: Examples of 3D Materials Science, J. Mater. Res. Technol. 1 (2012) 42-54. doi:10.1016/S2238-7854(12)70009-1.

[2] D.D. Gu, W. Meiners, K. Wissenbach, R. Poprawe, Laser additive manufacturing of metallic components: materials, processes and mechanisms, Int. Mater. Rev. 57 (2012) 133-164. doi:10.1179/1743280411Y.0000000014.

[3] C. Körner, Additive manufacturing of metallic components by selective electron beam melting — a review, Int. Mater. Rev. (2016) 1-17. doi:10.1080/09506608.2016.1176289.

[4] E.O. Olakanmi, R.F. Cochrane, K.W. Dalgarno, A review on selective laser sintering/melting (SLS/SLM) of aluminium alloy powders: Processing, microstructure, and properties, Prog. Mater. Sci. 74 (2015) 401-477. doi:10.1016/j.pmatsci.2015.03.002.

[5] W.E. Frazier, Metal Additive Manufacturing: A Review, J. Mater. Eng. Perform. 23 (2014) 1917-1928. doi:10.1007/s11665-014-0958-z. 
[6] S. Tammas-Williams, H. Zhao, F. Léonard, F. Derguti, I. Todd, P.B. Prangnell, XCT analysis of the influence of melt strategies on defect population in $\mathrm{Ti}-6 \mathrm{Al}-4 \mathrm{~V}$ components manufactured by Selective Electron Beam Melting, Mater. Charact. 102 (2015) 47-61. doi:10.1016/j.matchar.2015.02.008.

[7] L. Le Guéhennec, A. Soueidan, P. Layrolle, Y. Amouriq, Surface treatments of titanium dental implants for rapid osseointegration, Dent. Mater. 23 (2007) 844-854. doi:10.1016/j.dental.2006.06.025.

[8] A.J. Pinkerton, L. Li, An investigation of the effect of pulse frequency in laser multiple-layer cladding of stainless steel, Appl. Surf. Sci. 208-209 (2003) 405-410. doi:10.1016/S01694332(02)01420-4.

[9] W.S. Gora, Y. Tian, A.P. Cabo, M. Ardron, R.J. Maier, P.B. Prangnell, N.J. Weston, D.P. Hand, Enhancing surface finish of additively manufactured titanium and cobalt chrome elements using laser based finishing, in: 9th Int. Conf. Photonic Technol. - LANE 2016, Furth, Germany, 2016.

[10] M. Gharbi, P. Peyre, C. Gorny, M. Carin, S. Morville, P. Le Masson, D. Carron, R. Fabbro, Influence of a pulsed laser regime on surface finish induced by the direct metal deposition process on a Ti64 alloy, J. Mater. Process. Technol. 214 (2014) 485-495. doi:10.1016/j.jmatprotec.2013.10.004.

[11] M. Rombouts, G. Maes, W. Hendrix, E. Delarbre, F. Motmans, Surface Finish after Laser Metal Deposition, Phys. Procedia. 41 (2013) 810-814. doi:10.1016/j.phpro.2013.03.152.

[12] K. Dalgarno, Materials research to support high performance RM parts, in: Manuf. 2nd Int. Conf., Loughborough University, 2007: pp. 147-156.

[13] M. Rombouts, J.P. Kruth, L. Froyen, P. Mercelis, Fundamentals of Selective Laser Melting of alloyed steel powders, CIRP Ann. - Manuf. Technol. 55 (2006) 187-192. doi:10.1016/S00078506(07)60395-3.

[14] N.K. Tolochko, S.E. Mozzharov, I.A. Yadroitsev, T. Laoui, L. Froyen, V.I. Titov, M.B. Ignatiev, Balling processes during selective laser treatment of powders, http://dx.doi.org/10.1108/13552540410526953. (2013).

[15] K.A. Mumtaz, N. Hopkinson, Selective Laser Melting of thin wall parts using pulse shaping, J. Mater. Process. Technol. 210 (2010) 279-287. doi:10.1016/j.jmatprotec.2009.09.011.

[16] M. Jamshidinia, R. Kovacevic, The influence of heat accumulation on the surface roughness in powder-bed additive manufacturing, Surf. Topogr. Metrol. Prop. 3 (2015) 14003. doi:10.1088/2051-672X/3/1/014003.

[17] G. Strano, L. Hao, R.M. Everson, K.E. Evans, Surface roughness analysis, modelling and prediction in selective laser melting, J. Mater. Process. Technol. 213 (2013) 589-597. doi:10.1016/j.jmatprotec.2012.11.011.

[18] X. Wang, Y. Fu, H. Gao, Finishing of Additively Manufactured Metal Parts by Abrasive Flow Machining, in: Proc. 27th Annu. Int. Solid Free. Fabr. Symp., Austin, TX, 2016: pp. 24702472. https://sffsymposium.engr.utexas.edu/sites/default/files/2016/197-Wang.pdf (accessed March 20, 2017).

[19] S.S. Kumar, S.S. Hiremath, A Review on Abrasive Flow Machining (AFM), Procedia Technol. 25 (2016) 1297-1304. doi:10.1016/j.protcy.2016.08.224.

[20] S. Marimuthu, A. Triantaphyllou, M. Antar, D. Wimpenny, H. Morton, Laser polishing of selective laser melted Components, Int. J. Mach. Tools Manuf. (2015). doi:10.1016/j.ijmachtools.2015.05.002.

[21] J. Lambarri, J. Leunda, C. Soriano, C. Sanz, Laser Surface Smoothing of Nickel-based Superalloys, Phys. Procedia. 41 (2013) 255-265. doi:10.1016/j.phpro.2013.03.077. 
[22] F.E. Pfefferkorn, N.A. Duffie, X. Li, M. Vadali, C. Ma, Improving surface finish in pulsed laser micro polishing using thermocapillary flow, CIRP Ann. - Manuf. Technol. 62 (2013) 203-206. doi:10.1016/j.cirp.2013.03.112.

[23] J. Kumstel, B. Kirsch, Polishing Titanium- and Nickel-based Alloys using Cw-Laser Radiation, Phys. Procedia. 41 (2013) 362-371. doi:10.1016/j.phpro.2013.03.089.

[24] S. Heidrich, A. Richmann, P. Schmitz, E. Willenborg, K. Wissenbach, P. Loosen, R. Poprawe, Optics manufacturing by laser radiation, Opt. Lasers Eng. 59 (2014) 34-40. doi:10.1016/j.optlaseng.2014.03.001.

[25] A.M.K. Hafiz, E. V. Bordatchev, R.O. Tutunea-Fatan, Influence of overlap between the laser beam tracks on surface quality in laser polishing of AISI H13 tool steel, J. Manuf. Process. 14 (2012) 425-434. doi:10.1016/j.jmapro.2012.09.004.

[26] C.P. Ma, Y.C. Guan, W. Zhou, Laser polishing of additive manufactured Ti alloys, Opt. Lasers Eng. 93 (2017) 171-177. doi:10.1016/j.optlaseng.2017.02.005.

[27] D. Bhaduri, P. Penchev, A. Batal, S. Dimov, S.L. Soo, S. Sten, U. Harrysson, Z. Zhang, H. Dong, Laser polishing of 3D printed mesoscale components, Appl. Surf. Sci. 405 (2017) 2946. doi:10.1016/j.apsusc.2017.01.211.

[28] E. Yasa, J.-P. Kruth, J. Deckers, Manufacturing by combining Selective Laser Melting and Selective Laser Erosion/laser re-melting, CIRP Ann. - Manuf. Technol. 60 (2011) 263-266. doi:10.1016/j.cirp.2011.03.063.

[29] T.L. Perry, D. Werschmoeller, X. Li, F.E. Pfefferkorn, N.A. Duffie, Pulsed laser polishing of micro-milled Ti6Al4V samples, J. Manuf. Process. 11 (2009) 74-81. doi:10.1016/j.jmapro.2009.10.001.

[30] P.S. Davies, B.P. Wynne, W.M. Rainforth, M.J. Thomas, P.L. Threadgill, Development of Microstructure and Crystallographic Texture during Stationary Shoulder Friction Stir Welding of Ti-6Al-4V, Metall. Mater. Trans. A. 42 (2011) 2278-2289. doi:10.1007/s11661-011-0606-2.

[31] P.S. Davies, An investigation of microstructure and texture evolution in the Near- $\alpha$ titanium alloy timetal 834, University of Sheffield, 2009.

[32] G. Lütjering, J. Williams, Fundamental Aspects, in: Titanium, 2nd Editio, Springer Berlin Heidelberg, Berlin, Heidelberg, 2007: pp. 15-52. doi:10.1007/978-3-540-73036-1_2.

[33] A.A. Antonysamy, J. Meyer, P.B. Prangnell, Effect of build geometry on the $\beta$-grain structure and texture in additive manufacture of Ti6Al4V by selective electron beam melting, Mater. Charact. 84 (2013) 153-168. doi:10.1016/j.matchar.2013.07.012.

[34] H. Zhao, A.A. Antonysamy, J. Meyer, O. Ciuca, S.T. Williams, P.B. Prangnell, Automated Multi-Scale Microstructure Heterogeneity Analysis of Selective Electron Beam Melted TiAl6V4 Components, in: TMS 2015 144th Annu. Meet. Exhib., Springer International Publishing, Cham, 2015: pp. 429-436. doi:10.1007/978-3-319-48127-2_54.

[35] T. Ahmed, H.J. Rack, Phase transformations during cooling in $\alpha+\beta$ titanium alloys, Mater. Sci. Eng. A. 243 (1998) 206-211. doi:10.1016/S0921-5093(97)00802-2.

[36] W. Xu, M. Brandt, S. Sun, J. Elambasseril, Q. Liu, K. Latham, K. Xia, M. Qian, Additive manufacturing of strong and ductile $\mathrm{Ti}-6 \mathrm{Al}-4 \mathrm{~V}$ by selective laser melting via in situ martensite decomposition, Acta Mater. 85 (2015) 74-84. doi:10.1016/j.actamat.2014.11.028.

[37] J. Lin, N. Ma, Y. Lei, H. Murakawa, Measurement of residual stress in arc welded lap joints by $\cos \alpha$ X-ray diffraction method, J. Mater. Process. Technol. 243 (2017) 387-394. doi:10.1016/j.jmatprotec.2016.12.021.

[38] A.V. Gusarov, M. Pavlov, I. Smurov, Residual Stresses at Laser Surface Remelting and Additive Manufacturing, Phys. Procedia. 12 (2011) 248-254. doi:10.1016/j.phpro.2011.03.032.

[39] A. Kouadri-Henni, C. Seang, B. Malard, V. Klosek, Residual stresses induced by laser welding 
process in the case of a dual-phase steel DP600: Simulation and experimental approaches, Mater. Des. 123 (2017) 89-102. doi:10.1016/j.matdes.2017.03.022. 